Journal of Animal and Veterinary Advances 11 (16): 2995-2999, 2012

ISSN: $1680-5593$

(C) Medwell Journals, 2012

\title{
Carcass Characterization of Bulls Slaughtered Between 14 and 26 Months Using the Principal Component Analysis
}

\author{
${ }^{1,2}$ A. Slimene, ${ }^{1} \mathrm{C}$. Damergi, ${ }^{2} \mathrm{~L}$. Chammakhi, ${ }^{1} \mathrm{~T}$. Najar, ${ }^{3} \mathrm{M}$. Jbeli and ${ }^{1} \mathrm{M}$. Ben Mrad \\ ${ }^{1}$ National Institute of Agronomy of Tunisia 43, Charle Nicolle 1083 Tunis, Tunisia \\ ${ }^{2}$ Interprofessional Group of Red meats and Milk 8, Claude Bernard 1002 Tunis, Tunisia \\ ${ }^{3}$ Ministry of Military Defense of Tunisia Bab Mnara 1008 La kasba-Tunis, Tunisia
}

\begin{abstract}
A total of 170 carcasses of bulls aged between 14 and 26 months were studied for their characterization in terms of conformation and fatness degree using morphometric measurements. The slaughtered bulls are mainly Holstein, Limousin, Charolais and Crossbred beef. Carcass measurements performed at the slaughterhouse were length of the carcass, perimeter of the hind leg, depth of the carcass, length and thickness of the hind leg. Hot carcass weight, thickness of fat cover at the sixth rib and kidney fat weight were recorded. Carcass characterization was performed using principal component analysis and cluster analysis using Ward Method. The results showed the existence of four groups of carcasses: with a low conformation and a small frame size. Carcasses with an average conformation and a large frame size. Carcasses with a fairly good conformation and a small frame size. Carcasses with a good conformation and a large frame size. In conclusion, this study provides valuable information for the characterization of carcasses of bulls slaughtered in Tunisia. It also provides useful information for establishing a beef carcass classification grid in an attempt to meet the needs of the red meat sector operators and allows a balance between the price and the quality of marketed carcasses.
\end{abstract}

Key words: Carcass measurements, bulls, classification, component analysis, Tunisia

\section{INTRODUCTION}

Several countries worldwide have established systems of bovine carcasses classification to a better balance between the market prices and the quality of the carcasses marketed. The systems used in the European countries, the United States, Japan, Australia and Canada have identified several parameters for the establishment of a carcass classification grid allowing a better assessment of their conformations and marketing prices. In Tunisia, however, there is no carcass classification grid butchers make the transactions of carcasses purchase and sale mainly through a subjective assessment of fattening degree and conformation. Hence, there is a need to develop a carcass classification grid based on objective measures to determine the different classes of carcasses available on the market. This will facilitate commercial tasks between the various operators involved in the red meat industry.

Several researchers use a multivariate and a principal component analysis to characterize carcass from many species such as beef cattle, sheep and goats (Alberti et al., 2008, 2005; Santos et al., 2008; Spanghero et al., 2004; Destefanis et al., 2000;
Laville et al., 1996). Others use carcass measurements to determine carcass characteristics of several beef breeds at different ages and to identify variability between dairy and beef breeds (Clarke et al., 2009; Campion et al., 2009; Denk and Yilmaz, 2009). However, measurements on the beef carcasses were taken to establish the relationship between different measurement and retail cuts and carcass cutability (Cross et al., 1973; Epley et al., 1970; Abraham et al., 1968).

The main objective of this study is to identify parameters that characterize carcasses of young bulls aged between 14 and 26 months based on objective carcass measurements to distinguish between the different groups of carcasses found in Tunisian market red meat.

\section{MATERIALS AND METHODS}

A total of 170 young bulls were used for the characterization of beef carcasses after slaughter. Animals were local Holstein (109) and young bulls imported from France (61). Breeds were Limousine (13), Charolais (35) and crossbred beef (13). Holstein animals were slaughtered at an average age of 18 months. While for

Corresponding Author: A. Slimene, National Institute of Agronomy of Tunisia 43, Charle Nicolle 1083 Tunis, Tunisia 
other beef breeds was 19 months. Carcass weights recorded were $236,409,413,418 \mathrm{~kg}$, respectively for Holstein, Charolais, Limousine and Crossbred bulls. Local Holstein young bulls were fed a diet based on concentrate, oat silage and hay offered ad libitum. However, imported animals were fed a diet based on concentrate and straw offered ad libitum.

The various recorded data on animals include the carcass weight, slaughter age and the thickness of fat cover according to the method of De Boer et al. (1974). Measurements performed on carcasses are:

- Length of the carcass, measured from the anterior edge of symphysis pubis to the middle of the anterior edge of the visible part of the rib

- Length of hind leg, measured from the medial malleolus of the tibia in a straight line to the anterior edge of the symphysis pubis

- Width of carcass, measured from the last sternebra to the dorsal tip of the spinous process of the sixth thoracic vertebra

- Depth of hind leg, measured as the horizontal distance between the outermost points on the anterior and posterior surface of the leg

- Perimeter of leg, the maximum measurement of the horizontal contour of the leg at the symphysis pubis level

Length and perimeter measurements were taken by tape measure whereas width and depth measurements were taken by caliper.

Statistical analysis were conducted by SAS Software Version 9.1 (SAS, 2002). A principal component analysis was performed using the variables for all 170 carcasses to determine the number of independent variables that allow characterizing and distinguishing between different groups of carcasses. In this analysis, two principal components were retained that the eigenvectors are

greater than or equal to 1 . Cluster analysis on principal components using the Ward Method was conducted to identify the different groups of carcasses.

\section{RESULTS AND DISCUSSION}

Table 1 shows means, standard deviations and the coefficient of variation of the studied variables. The coefficient of variation of some variables such as length of carcass, length of leg, depth of carcass is $<10 \%$ while some others like fat thickness, weight of kidney fat, carcass weight is $>30 \%$. These results were quiet similar to those reported by Alberti et al. (2005) for measurement recorded for carcass length, leg length and leg perimeter. Laville et al. (1996) found similar coefficient of variation for carcass length, leg length and carcass depth. However, Dernnan et al. (2008) reported lower coefficient of variation for fat thickness.

Coefficients of correlation among carcass traits are given in Table 2 . Correlations between carcass weight and leg depth and perimeter were significantly high. However, depth of carcass shows a negative correlation between all variables except for both length parameters such as leg length and carcass length. In addition, high positive correlation were found between carcass weight, fat cover and dressing percentage. Alberti et al. (2005) reported

Table 1: Means, standard deviation and coefficient of variance of the variables measured on the carcass

\begin{tabular}{lrrr}
\hline Variables & Mean & SD & CV \\
\hline Age (month) & 19.02 & 2.38 & 12.55 \\
Carcass weight (kg) & 299.75 & 89.79 & 30.50 \\
Length of carcass (cm) & 134.52 & 4.40 & 3.27 \\
Width of carcass (cm) & 39.66 & 2.39 & 6.03 \\
Length of leg (cm) & 85.15 & 2.62 & 3.08 \\
Perimeter of the leg (cm) & 116.75 & 9.50 & 8.13 \\
Depth of leg (cm) & 28.20 & 3.80 & 13.49 \\
Fat thickness (mm) & 4.32 & 2.11 & 49.07 \\
Weight of kidney fat (kg) & 4.25 & 1.32 & 31.10 \\
Dressing percentage (\%) & 55.43 & 4.80 & 8.65 \\
Carcass blockiness index & 2.22 & 0.04 & 13.71 \\
\hline
\end{tabular}

Table 2: Correlation coefficient among variable of different bulls

\begin{tabular}{|c|c|c|c|c|c|c|c|c|c|c|c|}
\hline Parameters & AGE & $\mathrm{LC}$ & $\mathrm{DC}$ & LL & LD & $\mathrm{PL}$ & $\mathrm{CW}$ & FKW & $\mathrm{FC}$ & DP & CBI \\
\hline \multicolumn{12}{|l|}{ AGE } \\
\hline $\mathrm{LC}$ & $0.34^{\text {* *k*k }}$ & & & & & & & & & & \\
\hline DC & 0.05 & $0.17^{*}$ & & & & & & & & & \\
\hline LL & $0.12^{* * *}$ & $0.50^{\text {*k*** }}$ & $0.29^{* * * *}$ & & & & & & & & \\
\hline $\mathrm{LD}$ & 0.12 & 0.12 & 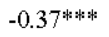 & 0.06 & & & & & & & \\
\hline PL & $0.24^{* * *}$ & $0.21^{* * *}$ & $-0.24^{\text {****** }}$ & 0.12 & $0.89^{* * * * * * *}$ & & & & & & \\
\hline CW & $0.12^{* * *}$ & $0.26^{*}$ & $-0.46^{* * * * *}$ & 0.10 & $0.89 * * * *$ & $0.91^{* * * * * * *}$ & & & & & \\
\hline FKW & $0.23^{* * *}$ & 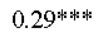 & $-0.22^{* * *}$ & $0.20^{* * *}$ & $0.43^{\text {* * * * * * }}$ & $0.50^{\text {***** }}$ & 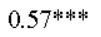 & & & & \\
\hline $\mathrm{FC}$ & $0.22^{* * *}$ & $0.24 * *$ & $-0.33^{\text {****** }}$ & 0.13 & $0.75^{* * * * *}$ & $0.75^{* * * * *}$ & $0.80^{\text {*k* } * *}$ & $0.58^{* * * * * * *}$ & & & \\
\hline DP & $0.16^{*}$ & $0.16^{*}$ & $-0.54^{* * * * *}$ & 0.01 & $0.83^{* * * * * *}$ & $0.87^{* * * * *}$ & $0.93^{* * * * * *}$ & 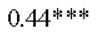 & 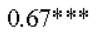 & & \\
\hline CBI & $0.17^{*}$ & $0.15^{*}$ & $-0.49^{* * * * *}$ & 0.04 & $0.90^{\text {* * * * * * }}$ & $0.91^{\text {****** }}$ & 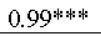 & 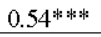 & $0.79^{\text {* * * * * * * }}$ & 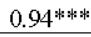 & \\
\hline
\end{tabular}


similar results for the correlation between the length of the leg and the leg perimeter. They also found a negative correlation between width of carcass and other measures taken on the carcass. Laville et al. (1996) reported lower correlations coefficients between carcass weight, length of leg and carcass length. Epley et al. (1970) reported similar correlation values between kidney fat and carcass weight. However, correlation between carcass weight and fat cover reported in the studies were higher than those reported by these researchers. Correlations between carcass weight, leg length and round depth reported by Abraham et al. (1968) were lower than those found in this study. Correlation coefficient between carcass weight and length of carcass reported by these researchers is higher than result shown in the study. Correlation between carcass weight and dressing percentage found in this study were higher than those reported by Wilson et al. (1964). However, these researchers reported lower coefficient of correlations between carcass weight, fat cover and kidney fat percentage than those found in the study. Berry et al. (1973) found negative correlation coefficient between different carcasses varying in length. Results reported by these researchers are not in concordance with those found in the study.

Table 3 and 4 shows the results of the principal component analysis of the parameters of carcass quality. Two main components in descending order were extracted in this analysis. The first component explained $63.26 \%$ of the variability whereas component 2 explained $13.35 \%$. These two components explained about $76.61 \%$ of the total variability.

Results on Table 4 showed high correlations between the first component, carcass weight $(r=0.97)$, thickness of the hind leg $(r=0.95)$, perimeter of the hind leg $(r=0.96)$,

Table 3: Results from the component analysis for the two first principal

\begin{tabular}{lccc}
\hline \multicolumn{2}{c}{ components } & & \\
\hline Component & Eigen values & $\begin{array}{c}\text { Proportion } \\
\text { of variance (\%) }\end{array}$ & $\begin{array}{c}\text { Cumulative } \\
\text { variance (\%) }\end{array}$ \\
\hline 1 & 9.48 & 0.6326 & 0.6326 \\
2 & 2.00 & 0.1335 & 76.6100 \\
\hline
\end{tabular}

Table 4: Principal component loading

\begin{tabular}{llr}
\hline Parameters & CP1 & CP2 \\
\hline Age & 0.220 & 0.560 \\
CW & 0.970 & 0.040 \\
LD & 0.950 & -0.077 \\
PL & 0.960 & 0.042 \\
DP & 0.910 & -0.080 \\
FC & 0.820 & 0.130 \\
FKW & 0.570 & 0.320 \\
CBI & 0.970 & -0.050 \\
LC & 0.200 & 0.790 \\
LL & 0.084 & 0.780 \\
DC & -0.470 & 0.470 \\
\hline
\end{tabular}

Carcass Weight (CW); Length of Carcass (LC);Depth of Carcass (DC) Length of hind Leg (LL); Carcass fat Cover (FC); Fat Kidney Weight (FKW); Carcass Blockiness Index (CBI); Perimeter of the Leg (PL); Dressing Percentage (DP); Depth of the Leg (LD) carcass yield $(r=0.91)$, thickness of fat cover $(r=0.82)$ and carcass blockiness index $(r=0.97)$. On the other hand, the chest depth of the carcass showed a negative correlation with the first component $(\mathrm{r}=-0.47)$. The second component had a high positive correlation with the length of the carcass $(r=0.79)$ and that of the hind leg and $(\mathrm{r}=0.78)$.

Alberti et al. (2005) have shown in a principal component analysis for the measurements of the carcass similar results compared to those recorded in the study. Indeed, these researchers showed that the first component explains a variation of about $57.61 \%$ while the second describes an approximate variation of about $19.62 \%$. Besides, the principal component analysis performed by the same researchers for the parameters measured at the carcass, mainly for those related to the length of the carcass and that of the hind leg showed high correlation coefficients with the second principal component. Correlations coefficients recorded were in $r=0.87$ and $r=0.69$, respectively for the carcass length and the length of the hind leg. Such results are consistent with those obtained in the present study.

Laville et al. (1996) conducted a study on Charolais bulls slaughtered at the age of 18 months in which they made measurements on their carcasses to study the correlations between the different measured parameters. They shown the existence of a weak correlation between the carcass weight and the parameters related to the length of the carcass $(r=0.08)$ and that of the hind leg $(\mathrm{r}=0.34)$. These results are close to correlations values recorded in The experience. Indeed, researchers found a correlation value 0.26 for the relationship between the carcass weight and the length of the carcass and of 0.10 for that of the length of the hind leg with the carcass weight.

Alberti et al. (2008) performed a principal component analysis of 15 European beef breeds in according to their carcass characteristics in order to reflect their production aptitude. They reported that the first components explained about $48.8 \%$ of carcass variability. The first component was basically related to parameters with regards to blockiness index, dressing percentage and carcass weight. However, the second components explained $24.5 \%$ and was related to fat percentage and kidney fat weight. These results are quiet similar to those found in this study.

Figure 1 shows the 11 initial variables in the plane formed by the axes representing the two main components 1 and 2. The coordinates of these variables are the correlations of variables with these components ( 1 and 2). Component 1 presented a high positive correlation with the carcass weight, the blockiness index while the 


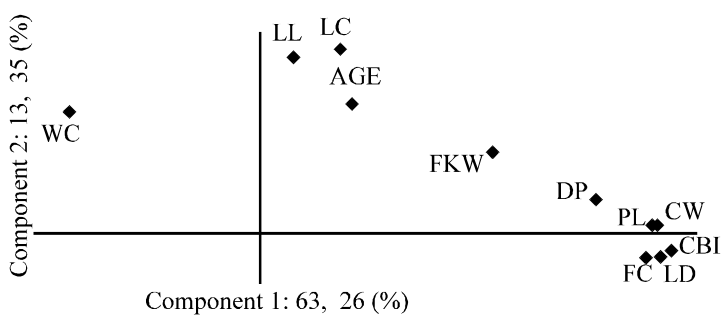

Fig. 1: Projection of the carcass traits measures in the plane defined by the two first components (PCs). Carcass Weight (CW); Length of Carcass (LC); Depth of Carcass (DC) Length of hind Leg (LL); Carcass Fat Cover (FC); Fat Kidney Weight (FKW); Carcass Blockiness Index (CBI); Perimeter of the Leg (PL); Dressing Percentage (DP); Depth of the Leg (LD)

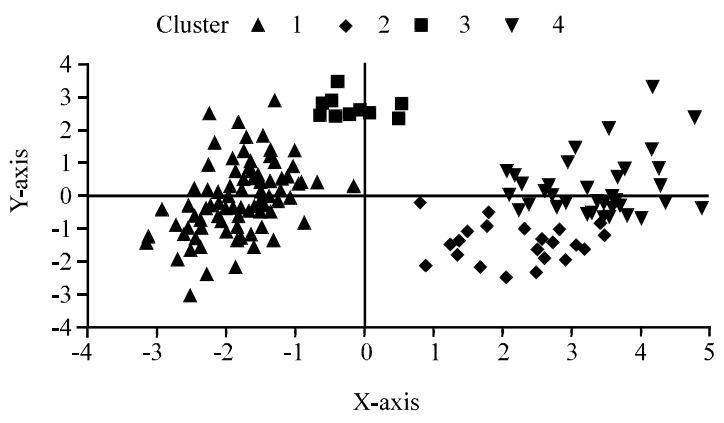

Fig. 2: Projection of the carcass trait measures of the four animal groups identified by the cluster analysis based on the two principal components

thickness of the hind leg is negatively correlated with the depth of the chest and that of the carcass as well. On the other hand, the two components presented a high positive correlation with the length of the hind leg and that of the carcass.

Principal component analysis allowed identifying two groups of variables. The first principal component is correlated with variables related to the conformation of the carcass and meat yield whereas the second principal component can be considered as an indicator of the axis of the carcass bone structure.

Results of cluster analysis are shown in Fig. 2. In fact, cluster analysis based on the two earlier identified components revealed the identification of four classes of carcasses as follows:

- Cluster 1: bulls with a low carcass weight, a low conformation and a small size carcass

- Cluster 2: bulls with heavy carcass weight, a pretty good conformation and a small size carcass
- Cluster 3: bulls with an average carcass weight, an average conformation and a large size carcass

- Cluster 4: bulls with a very heavy carcass weight, a good conformation and a large size carcass

\section{CONCLUSION}

This study revealed the importance of carcass measurements in the assessment and the qualification of carcass obtained from bulls aged between 14 and 26 months. The use of the principal component analysis allowed the identification of two groups of components as well as the distinction between the different classes of carcasses. Cluster analysis permitted the distinction between the different groups of carcasses marketed in Tunisia. Moreover, the results of the present study provide valuable information regarding the carcass weight and the length of the carcass associated to the fat cover thickness that could be used to develop a classification gird for carcasses in Tunisia. Such a gird serves as a basis for the negotiation between meat sector operators.

\section{ACKNOWLEDGEMENTS}

Researchers thank the Ellouhoum slaughterhouse and the Ministry of Military Defense for being so helpful with the slaughter carcass measurements.

\section{REFERENCES}

Abraham, H.C., Z.L. Carpenter, G.T. King and O.D. Butler, 1968. Relationship of carcass weight, conformation and carcass measurements and their use in predicting beef carcass cutability. J. Anim. Sci., 27: 604-610.

Alberti, P., B. Panea, C. Sanudo, J.L. Olleta and G. Ripoll et al., 2008. Live weight, body size and carcass characteristics of young bulls of fifteen European breeds. Livest. Sci., 114: 19-30.

Alberti, P., G. Ripoli, F. Goyache, F. Lahoz, J.L. Olletta, B. Panea and C. SaNudo, 2005. Carcass characterization of seven Spanish beef breeds slaughtered at two commercial weights. Meat. Sci., 7: 514-521.

Berry, B.W., G.C. Smith and Z.L. Carpenter, 1973. Beef carcass length and yields of boneless retail cuts. J. Anim. Sci., 37: 1132-1136.

Campion, B., M.G. Keane, A. Kenny and D.P. Berry, 2009. Evaluation of estimated genetic merit for carcass weight in beef cattle: Blood metabolites, carcass measurements, carcass composition and select non-carcass components. Livest. Sci., 126: 100-111. 
Clarke, A.M., M.J. Dernnan, M. McGee, D.A. Kenny, R.D. Evans and D.P. Berry, 2009. Intake, live animal scores/measurements and carcass composition and value of late-maturing beef and dairy breeds. Livest. Sci., 126: 57-68.

Cross, H.R., Z.L. Carpenter and G.C. Smith, 1973. Equations for estimating boneless retail cut yields from beef carcasses. J. Anim. Sci., 37: 1267-1272.

De Boer H., B.L. Dumont, R.W. Pomery and J.H. Weniger, 1974. Manuel on E.A.A.P. reference methods for the assessment of carcass characteristics in cattle. Livest. Prod. Sci., 1: 151-164.

Denk, H. and O. Yilmaz, 2009. Slaughter and carcass traits of young brown swiss bulls raised in semi-intensive system. J. Anim. Vet. Adv., 8: 2186-2189.

Dernnan, M.J., M. McGee and M.G. Keane, 2008. The value of muscular and skeleta 1 scores in the live animal and carcass classification sores as indicators of carcass composition in cattle. Animal, 2: 752-760.

Destefanis, G., M.T. Barge, A. Brugiapaglia and S. Tassone, 2000. The use of Principal Component Analysis (PCA) to characterize beef. Meat Sci., 56: 255-259.
Epley, R.J., H.B. Hedrick, W.C. Stringer and D.P. Hutcheson, 1970. Predisction of weight and percent retail cuts of beef using five carcass measurements. J. Anim. Sci., 30: 872-879.

Laville, E., V. Martin and O. Bastien, 1996. Prediction of composition traits of young charolais bull carcass using a morphometric method. Meat Sci., 44: 93-104.

SAS, 2002. User's Guide Statistics. 9.1 Ver., SAS Institute, Inc., Cary, NC, USA.

Santos, V.A.C., A.M.D. Silva, S.R. Silvestre and J.M.T. Azevado, 2008. The use of multivariate analysis to characterize carcass and meat quality of goat kids protected by the PGI Cabrito De barroso. Livest. Sci., 116: 70-81.

Spanghero, M., L. Gracco, R. Valusso and Piasentier, 2004. In vivo performance, slaughtering traits and meat quality of bovine (Italian Simmental) and buffalo (Italian Mediterranean) bulls. Livest. Prod. Sci., 91: 129-141.

Wilson, L.L., C.A. Dinkel, H.J. Tuma and J.A. Minyard, 1964. Live-animal prediction of cutability and other beef carcass characteristics by several judges. J. Anim. Sci., 23: 1102-1107. 